\title{
Upregulation of Id3 inhibits cell proliferation and induces apoptosis in A549/DDP human lung cancer cells in vitro
}

\author{
FANGFANG CHEN $^{1}$, QINFEI ZHAO ${ }^{1}$, SHUXIA WANG ${ }^{1}$, HAIYONG WANG $^{1}$ and XIAOJUN LI ${ }^{1,2}$ \\ ${ }^{1}$ Center of Clinical Laboratory Science, Jinling Hospital, School of Medicine, Southern Medical University, \\ Nanjing, Jiangsu 210002; ${ }^{2}$ State Key Laboratory of Analytical Chemistry for Life Science, Department of Chemistry, \\ Nanjing University, Nanjing, Jiangsu 210093, P.R. China
}

Received May 19, 2015; Accepted March 23, 2016

DOI: $10.3892 / \mathrm{mmr} .2016 .5221$

\begin{abstract}
Inhibitor of DNA binding (Id)3 is a member of the Id multigene family of dominant-negative helix-loop-helix transcription factors, which function as oncogenes or tumor suppressors in human cancers. Its upregulation was recently shown to have inhibitory effects on lung cancer, which is the leading cause of cancer-associated mortality worldwide. As drug resistance represents a major bottleneck of cancer therapy, the present study assessed the ability of Id3 to inhibit cisplatin-resistant A549 lung adenocarcinoma cells (A549/DDP). A549/DPP cells were transiently transfected with enhanced green fluorescence protein overexpression plasmid (pEGFP) or Id3 overexpression plasmid (Id3/pEGFP), which was confirmed by confocal fluorescence microscopy, PCR and western blot analysis. The effects of Id3 on the viability and apoptosis of A549/DDP were determined using an MTT assay, fluorescence microscopy with Hoechst 33258 staining and flow cytometry following Annexin V/propidium iodide double staining. The results revealed that overexpression of Id3 significantly inhibited the proliferation and viability of A549/DDP cells in a time-dependent manner. Furthermore, overexpression of Id3 significantly increased the apoptotic rate of A549/DDP cells from 2.73 to $16.92 \%$, confirming the implication of Id 3 in the negative control of tumour growth. The results of the present study revealed that overexpression of Id 3 may serve as a novel strategy for inhibiting cisplatin-sensitive lung cancer. Further experiments will be performed to determine whether Id3 overexpression could enhance the sensitivity of lung cancer cells to DDP.
\end{abstract}

Correspondence to: Dr Xiaojun Li, Center of Clinical Laboratory Science, Jinling Hospital, School of Medicine, Southern Medical University, 305 East Zhongshan Road, Nanjing, Jiangsu 210002, P.R. China

E-mail: xiaojunli62@126.com

Key words: inhibitor of DNA binding 3, A549/DDP, proliferation, apoptosis

\section{Introduction}

Non-small-cell lung cancer (NSCLC) is the most frequent type of lung cancer and the most common cause of cancer-associated mortality (1). The poor outcome of NSCLC and patient survival are partly due to the development of drug resistance. At present, cisplatin-based chemotherapy is recommended as the first-line treatment for advanced NSCLC. Despite extensive research on its resistance mechanisms, pre-clinical data have not been incorporated into the selection of NSCLC patients or tailored treatment regimens in clinical trials. The current understanding of the molecular mechanisms of NSCLC and its chemoresistance requires to be expanded and applied for its treatment. It is important to identify novel biomarkers and therapeutic targets for NSCLC and provide a rationale to overcome the current therapeutic plateau.

Inhibitor of differentiation/DNA binding (Id) proteins, which are negative regulators of basic helix-loop-helix (bHLH) transcription factors, function as dominant-negative inhibitors of E-proteins by inhibiting their ability to bind DNA $(2,3)$. Four members of the Id family, ID1-4, occur in vertebrates. Id proteins have crucial roles in the coordinated regulation of a variety of cellular process, including cell growth, differentiation, apoptosis, tumorigenesis and carcinogenesis (4-6). Numerous studies have shown that the expressional regulation and functions of Ids are controlled by complex mechanisms, which are distinct for various cancer cell types and developmental stages (7-9).

The Id 3 gene is likely to have similar biological behaviors to those of other Ids, which have an important role in cell apoptosis. In B-lymphocyte progenitors, Id3 was found to induce cell growth arrest and caspase-3-dependent apoptosis (10). In immortalized human keratinocytes, Id3 as the apical gene in the mitochondrial pathway of cell death, is able to induce caspase-3- and -9-dependent apoptosis and mediate their UVB sensitization (11).

Id3 has been implicated in mediating apoptosis induced by cisplatin, a DNA-damaging chemotherapeutic agent. Cisplatin induced upregulation of Id 3 mRNA, and ectopic expression of Id3 sensitized MG-63 sarcoma cells to cisplatin-induced caspase-3 activation and growth inhibition (12). However, the exact induction mechanism was not described. Previous studies by our group showed that Id3 was downregulated in 
A549 human lung adenocarcinoma epithelial cells and that ectopic overexpression of Id3 in A549 cells inhibited their proliferation and induced apoptosis in vitro, as well as reducing tumor growth in vivo $(13,14)$. These results suggested that Id3, as an upstream gene of the apoptotic signaling cascade, can induce cell apoptosis.

The present study was the first to perform plasmid-mediated overexpression of Id3 in cisplatin-resistant A549 cells (A549/DDP) to assess its effect on the cells' proliferation and apoptotic rate. The results suggested that ectopic expression of Id3 may represent a promising approach for inhibiting chemoresistant NSCLC cells.

\section{Materials and methods}

Cell lines and culture. The cisplatin-resistant A549/DDP cell line and native A549 cells were purchased from the Cancer Institute of the Chinese Academy of Medical Sciences (Beijing, China). Cells were cultured in RPMI-1640 medium (HyClone Laboratories, Inc., Logan, UT, USA) supplemented with $10 \%$ fetal bovine serum (FBS; HyClone Laboratories, Inc.), $100 \mathrm{U} / \mathrm{ml}$ penicillin and $100 \mathrm{mg} / \mathrm{ml}$ streptomycin (HyClone Laboraties, Inc.) in an atmosphere containing $5 \% \mathrm{CO}_{2}$ at $37^{\circ} \mathrm{C}$. In all experiments, exponentially growing cells were used.

Transient transfection. Lipofectamine 2000 (Invitrogen; Thermo Fisher Scientific, Inc., Waltham, MA, USA) was used for transfection following the manufacturer's instructions. In brief, A549/DDP cells (0.5-2x105/well in $400 \mu 1$ medium) were seeded into 24-well plates and incubated for $24 \mathrm{~h}$ for attachment to reach $90-95 \%$ confluence. Enhanced green fluorescence protein-expressing plasmid (pEGFP) or $\operatorname{Id} 3 / \mathrm{pEGFP}(0.8 \mu \mathrm{g})$ and Lipofectamine $2000(2 \mu \mathrm{l})$ were each diluted separately in $50 \mu \mathrm{l}$ serum-free Opti-MEM (Gibco BRL, Thermo Fisher Scientific, Inc.) and incubated for $5 \mathrm{~min}$ at room temperature, followed by mixing of the respective plasmid and Lipofectamine 2000 solutions and incubation at room temperature for $20 \mathrm{~min}$. The cells were then incubated with this mixture $(100 \mu \mathrm{l})$ at $37^{\circ} \mathrm{C}$ for $12-72 \mathrm{~h}$ depending on the specific experiment and then subjected to further analysis.

Proliferation assay. The effects of DPP (Sigma-Aldrich, St. Louis, MO, USA) on native A549 and A594/DPP cells as well as the effects of Id3/pEGFP on A594/DPP cells were assessed using a 3-(4,5-dimethylthiazol-2-yl)-2,5-diphenyltetrazolium bromide (MTT) assay. In brief, cells were seeded into 96-well plates at $5 \times 10^{3}$ cells/well and allowed to attach overnight. Subsequently DPP was added at various concentrations $(0,0.5$, $1,2,5,10,15,20,30,40$ and $80 \mu \mathrm{g} / \mathrm{ml})$, followed by incubation for $24 \mathrm{~h}$. In another experiment, A594/DPP cells were transfected with pEGFP or Id3/pEGFP as described above for $12,24,48$ or $72 \mathrm{~h}$. The cell viability was then assessed by addition of $0.5 \mathrm{mg} / \mathrm{ml} \mathrm{MTT} \mathrm{(Sigma-Aldrich),} \mathrm{and} \mathrm{cells} \mathrm{were}$ incubated at $37^{\circ} \mathrm{C}$ for $4 \mathrm{~h}$. Then culture medium was removed and $150 \mu \mathrm{l}$ dimethyl sulfoxide (Sigma-Aldrich) was added, followed by agitation for $10 \mathrm{~min}$. The absorbance at $570 \mathrm{~nm}$ $\left(\mathrm{OD}_{570}\right)$ was measured by using a Multiskan MS microplate reader (Labsystems Diagnostics Oy, Vantaa, Finland) with a reference wavelength of $650 \mathrm{~nm}$. The experiment was repeated three times to generate a growth curve using the following formula: Proliferation rate $(\%)=\mathrm{OD}_{570}$ (experimental group) / $\mathrm{OD}_{570}$ (control group) x $100 \%$.

Reverse-transcription polymerase chain reaction (RT-PCR). Total RNA was extracted from cells using TRIzol ${ }^{\circledR}$ reagent (Invitrogen). Total RNA (1 $\mu \mathrm{g})$ was reverse-transcribed using the RevertAid First Strand cDNA Synthesis kit (Fermentas, Vilnius, Lithuania). PCR was performed in a total volume of $25 \mu \mathrm{l}$ containing $12.5 \mu \mathrm{l}$ Premix Ex Tag loading dye mix (Takara Bio Inc., Otsu, Japan), $7.5 \mu$ l double-distilled water, $1.5 \mu \mathrm{l}$ Id 3 forward primer (5'-ATGAAGGCGCTGAGC CCGGT-3'), $1.5 \mu \mathrm{l}$ Id3 reverse primer (5'-TTTGCCACTCGG CCGT-3') (both purchased from Invitrogen; Thermo Fisher Scientific, Inc.) and $2 \mu \mathrm{l}$ cDNA. Complementary DNA was amplified under the following reaction conditions: $94^{\circ} \mathrm{C}$ for $5 \mathrm{~min}$, followed by 35 amplification cycles of $94^{\circ} \mathrm{C}$ for $50 \mathrm{sec}$, $55^{\circ} \mathrm{C}$ for $50 \mathrm{sec}, 70^{\circ} \mathrm{C}$ for $50 \mathrm{sec}$ and final elongation at $72^{\circ} \mathrm{C}$ for $5 \mathrm{~min}$. Three independent experiments were performed to confirm reproducibility of the results.

Western blotanalysis. A549/DDP cells were cultured in six-well plates, transfected with pEGFP/Id3 for $24 \mathrm{~h}$, washed twice with ice-cold phosphate-buffered saline (PBS; pH 7.2), lysed in $200 \mu \mathrm{l}$ radioimmunoprecipitation assay buffer (Beyotime Institute of Biotechnology, Inc., Haimen, China) and recovered with a cell scraper. Protein concentrations were determined using the Enhanced BCA Protein Assay kit (Beyotime Institute of Biotechnology, Inc.). Samples (20 $\mu \mathrm{g})$ of the cellular lysate were denatured and fractionated by sodium dodecyl sulfate polyacrylamide gel electrophoresis [SDS-PAGE; 12\% (w/v) polyacrylamide gel] and transferred onto a polyvinylidene difluoride membrane (Millipore, Billerica, MA, USA) by semi-dry blotting (Bio-Rad Laboratories, Inc., Hercules, CA, USA). The membranes were blocked with Tris-buffered saline containing Tween 20 (TBST; Beyotime Institute of Biotechnology, Inc.) with $5 \%(\mathrm{w} / \mathrm{v})$ non-fat milk for $2 \mathrm{~h}$ and incubated with mouse monoclonal anti-hId3 (1:1,000 dilution; cat. no. ab55269; Abcam, Cambridge, MA, USA) or rabbit anti- $\beta$-actin (1:800 dilution; cat. no. sc-10731; Santa Cruz Biotechnology, Inc., Dallas, TX, USA) for $1 \mathrm{~h}$ at room temperature and overnight at $4^{\circ} \mathrm{C}$. After washing, the membranes were incubated with horseradish peroxidase (HRP)-conjugated goat anti-mouse immunoglobulin (Ig)G (1:400 dilution; Santa Cruz Biotechnology, Inc.) or HRP-conjugated goat anti-rabbit IgG (1:300 dilution; Santa Cruz Biotechnology, Inc.) for $2 \mathrm{~h}$ at room temperature. Antibody binding was detected using an enhanced chemiluminescence detection system (Millipore). The intensities of bands were measured using Quantity One ${ }^{\circledR}$ software (version 170-9600; Bio-Rad Laboratories, Inc.) with normalization to $\beta$-actin as the internal control.

Flow cytometric analysis. Apoptosis was quantified using AnnexinV-fluorescein isothiocyanate (FITC)/propidium iodide (PI) staining followed by flow cytometry. A549/DDP cells $\left(3.5 \times 10^{5}\right.$ cells/well) were cultured in six-well plates to $90 \%$ confluency, transfected for $24 \mathrm{~h}$, collected by trypsinization, washed twice with PBS and suspended in $100 \mu \mathrm{l}$ binding buffer containing $10 \mathrm{mM}$ 4-(2-hydroxyethyl)-1-piperazineethanesulfonic acid/ $\mathrm{NaOH}$ (pH 7.4), $140 \mathrm{mM} \mathrm{NaCl}$ and $2.5 \mathrm{mM} \mathrm{CaCl}_{2}$ (BD Biosciences, 


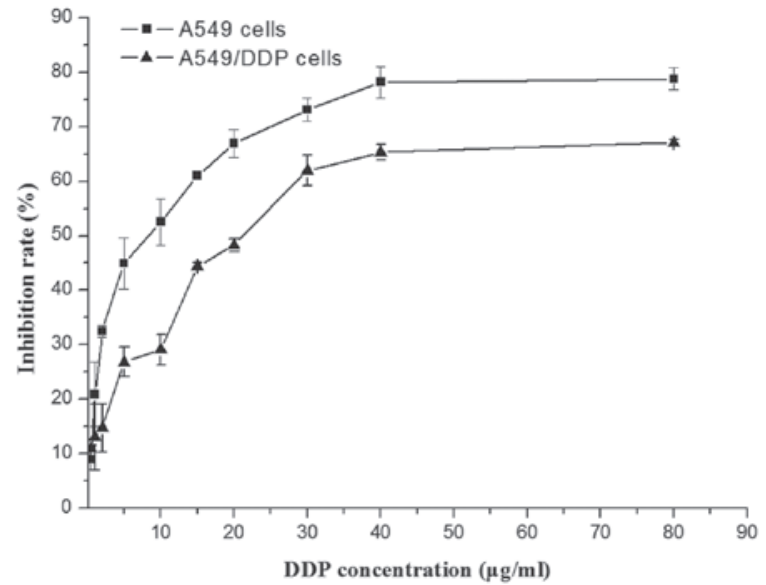

Figure 1. Cell growth inhibition rate of A549 and A549/DDP cells treated with different concentrations of cisplatin at $24 \mathrm{~h}(\mathrm{n}=3$; mean \pm standard deviation). The $\mathrm{IC}_{50}$ of different concentrations of cisplatinin A549 and A549/DDP at $24 \mathrm{~h}$ were significantly different $(\mathrm{P}<0.05)$ at each concentration. DPP, cisplatin.

Franklin Lakes, NJ, USA). $5 \mu$ l Annexin V-FITC and $5 \mu 1$ PI were then added to the wells, followed by incubation for $30 \mathrm{~min}$ at $37^{\circ} \mathrm{C}$ in the dark. Following dilution with $400 \mu \mathrm{l}$ binding buffer, staining was analyzed within $1 \mathrm{~h}$ by flow cytometry. The fluorescence intensity (green, FL1-H and red, FL2-H) was measured using a FACSCalibur flow cytometer (BD Biosciences). CellQuest Pro software (BD Biosciences) was used for acquisition and analysis of data.

Hoechst 33258 staining. In addition to flow cytometric analysis, apoptosis was also examined by nuclear staining with a Hoechst 33258 staining kit (Beyotime Institute of Biotechnology, Inc.). In brief, A549/DPP cells $\left(1.0 \times 10^{5}\right.$ cells/well) were grown on coverslips in 24 -well plates and transfected with the respective plasmids for $48 \mathrm{~h}$. Following two washes in PBS, cells were fixed in acetone at room temperature for $2 \mathrm{~h}$. Subsequent to rinsing with PBS, the cells were stained with $0.5 \mathrm{ml}$ Hoechst 33258 solution $(167 \mu \mathrm{m})$ in the dark for $5 \mathrm{~min}$. Following washing with PBS, cells were observed using a confocal fluorescence microscope (IX 71 Motorized Inverted Microsope; Olympus Corporation, Tokyo, Japan).

Statistical analysis. All data were analyzed using SPSS version 13.0 software (SPSS, Inc., Chicago, IL, USA). Values are expressed as the mean \pm standard deviation. One-way analysis of variance was used for statistical comparison. $\mathrm{P} \leq 0.05$ was considered to indicate a statistically significant difference between values.

\section{Results}

Determination of A549 and A549/DDP cell drug sensitivity. In order to assess the differential sensitivity of A549 and A549/DDP cells to DDP, cells were incubated with various concentrations of DDP for $24 \mathrm{~h}$ and subjected to an MTT assay. As shown in Fig. 1 the viability of A549 was reduced by DPP in a dose-dependent manner, while A549/DDP cells showed partial resistance against the drug. The $\mathrm{IC}_{50}$ value of
A549/DPP cells $(19.38 \pm 1.66 \mu \mathrm{g} / \mathrm{ml})$ was 3 -4-fold increased compared to that of the native A549 cells $(5.32 \pm 3.11 \mu \mathrm{g} / \mathrm{ml})$, confirming the drug resistance of the A549/DDP cell line.

Overexpression of Id3 in A549/DDP cells. Transfection with the eukaryotic expression vectors pEGFP or Id3/pEGFP for $24 \mathrm{~h}$ was successful, as indicated by confocal fluorescence microscopy (Fig. 2A). Furthermore, the overexpression of Id3 in A549/DDP cells transfected with Id3/pEGFP for $24 \mathrm{~h}$ was confirmed at the mRNA level by RT-PCR (Fig. 2B) and at the protein level by western blotting (Fig. 2C). There was significant difference in Id 3 transfected cells $(\mathrm{P}<0.05)$, but there was no significant difference in the EGFP vector group and blank control group ( $\mathrm{P}>0.05)$.

Id3 inhibits the proliferation of A549/DDP cells. To investigate the effects of Id 3 overexpression on the proliferation of A549/DDP cells, an MTT assay was performed. MTT analysis revealed that transfection with Id3/pEGFP for 12, 24, 48 or $72 \mathrm{~h}$ inhibited the proliferation of A549/DDP cells in a time-dependent manner, but there was no trend in pEGFP-transfected group (Fig. 3).

Id3 induces apoptosis in A549/DDP cells. Fluorescence microscopy following Hoechst 33258 staining revealed that A549/DDP cells transfected with Id3/pEGFP presented with apoptotic features, including partially ruptured nuclei as well as cells of different sizes and with shrunken or distorted nuclei, as indicated by conglomerated fluorescence that presented the appearance of grains. In comparison, only a very small proportion of cells in the pEGFP-transfected and control groups showed these apoptotic features (Fig. 4A). Flow cytometric analysis further confirmed the above results: As shown in Fig. 4B and C, increased levels of early apoptotic cells $(16.92 \pm 8.72 \%)$ were observed in the Id3/pEGFP-transfected group, while the proportion of early apoptotic cells in the untreated control or pEGFP-transfected groups was markedly lower $(2.73 \pm 2.54$ and $3.07 \pm 5.03 \%$, respectively). All of these results demonstrated that ectopic expression of Id3 induced apoptosis in A549/DDP cells.

\section{Discussion}

Lung cancer is the most frequent cancer type worldwide and its incidence increases by $0.5 \%$ per year (15). Despite major advances in disease management, chemotherapy and radiotherapy, almost $80 \%$ of all patients with lung cancer succumb to the disease within 1 year of diagnosis and long-term survival is achieved in only $5-10 \%$ of all cases $(15,16)$. The major obstacle in lung cancer chemotherapy is inherent and acquired drug resistance of the cancer cells $(17,18)$, which limits the efficacy of chemotherapy. Therefore, it is important to identify novel biomarkers for lung cancer which may be utilized as therapeutic targets.

Id3 is a member of the Id family of proteins and is a helix-loop-helix transcription factor. The tumor suppressor function of Id 3 has been reported in a variety of cancer types, including hepatocellular carcinoma (19), prostate cancer (20) and colorectal adenocarcinoma (21). Forced expression of Id 3 in head and neck squamous cell carcinoma cells reduced 
A
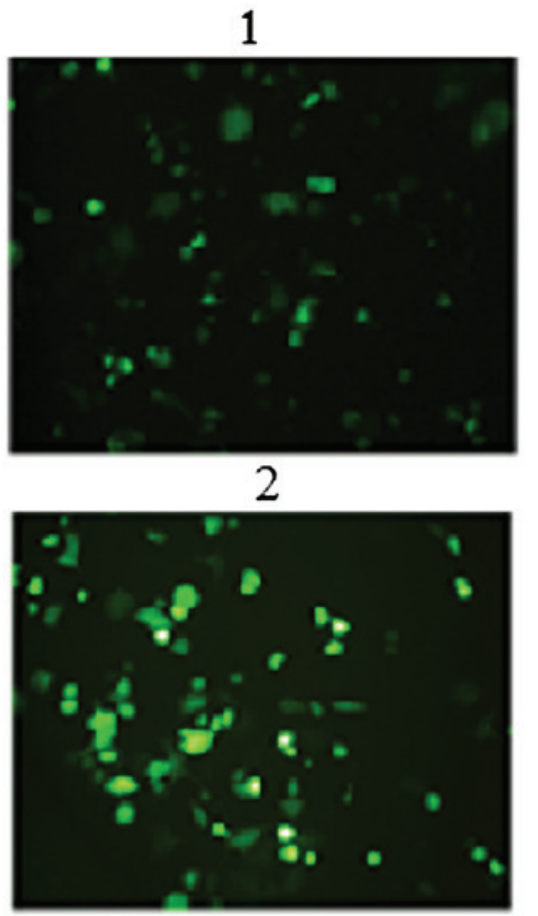

3

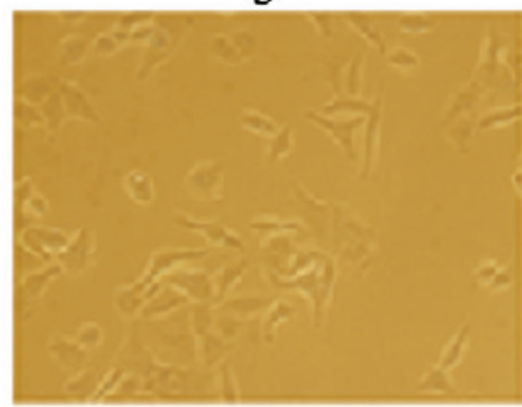

B

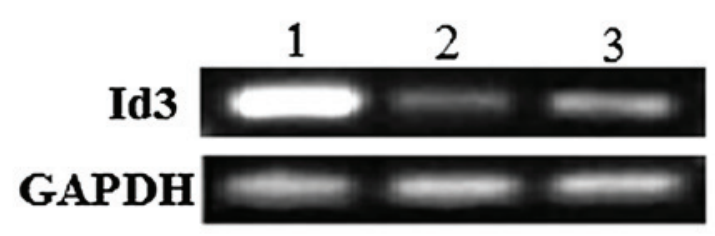

C

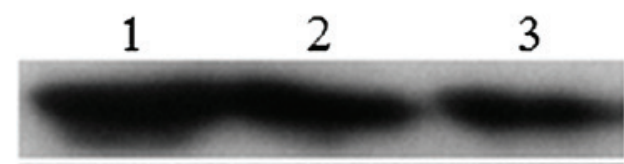

\section{及-actin}

Figure 2. Overexpression of Id3 in A549/DDP cells. (A) Immunofluorescence was used to detect Id3 expression via EGFP. Images shown are representative of three independent experiments (magnification, x200). (B and C) $24 \mathrm{~h}$ after transfection of A549/DDP cells with pEGFP or Id3/pEGFP, Id3 expression was detected (B) at the mRNA level by reverse-transcription polymerase chain reaction analysis with GAPDH used as an internal control and (C) at the protein level by western blot analysis with $\beta$-actin used as an internal control Lanes: 1, Id3/pEGFP transfectants; 2, pEGFP transfectants; 3, untreated control. Data from one of three or more representative experiments are shown EGFP, enhanced green fluorescence protein; Id3, inhibitor of DNA binding 3 .

their invasiveness interference with the transcription of matrix metalloproteinase 2 (22). In primary human colorectal adenocarcinomas, the expression of $\operatorname{Id} 1, \operatorname{Id} 2$ and $\operatorname{Id} 3$ was

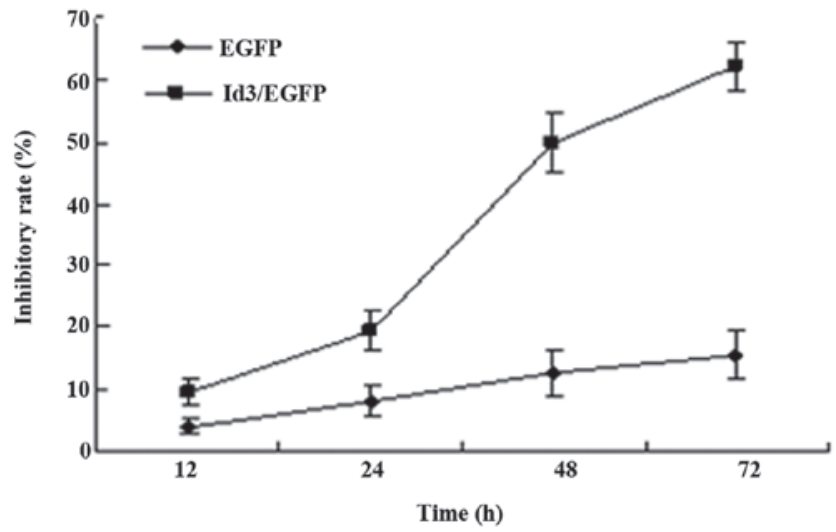

Figure 3. Time-dependent growth inhibitory effects of Id3 on A549/DDP cells. MTT analysis of the inhibitory effects of Id3 on A549/DDP cell proliferation at 12, 24, 48 and $72 \mathrm{~h}$ following transfection with Id3/pEGFP or pEGFP. Each experiment was performed in triplicate, and bars represent the mean \pm standard deviation. The proliferation or survival of A549/DDP cells was markedly inhibited by Id3/pEGFP. EGFP, enhanced green fluorescence protein; Id3, inhibitor of DNA binding 3.

found to be significantly increased compared with that in normal mucosa and correlated with the presence of mutated p53 $(23,24)$. Numerous studies have assessed the role of Id3 in various cancer types $(25,26)$. Previous studies by our group have shown that upregulation of Id3 inhibited the proliferation and induced apoptosis in A549 cells in vitro and in vivo $(13,14)$, while further study is required to determine the underlying mechanisms. Therefore, ectopic expression of Id3 may represent a novel strategy for treating NSCLC. However, the effects of Id3 on the drug resistant A549/DDP human lung cancer cell line have not been previously reported, to the best of our knowledge.

Apoptosis is a form of programmed cell death, which maintains the healthy survival/death balance in metazoan cells, while it is generally circumvented by cancer cells (27). Apoptosis induction is an important mechanism of action of anti-cancer agents. Numerous studies have focused on the manipulation of specific genes to enhance the sensitivity of cancer cells to drugs such as the DNA-damaging agent cisplatin $(28,29)$. High levels of Id 3 have been indicated to have a role in drug resistance and disease progression and Id 3 has been implicated in apoptosis in response to cisplatin. Treatment with cisplatin increased the mRNA levels of Id3 in MG-63 sarcoma cells, while ectopic expression of Id 3 sensitized them to cisplatin-induced caspase-3 activation and growth inhibition (12). The results of the present study showed that overexpression of Id3 significantly inhibited the growth of A549/DDP cells and induced apoptosis, indicating that high levels of Id3 protein expression may be a potential target for cisplatin resistance of lung adenocarinoma cells. The effects of DDP on A549/DPP cells transfected with Id3/pEGFP will be investigated in future studies.

The expression of Id3 is dependent on the cell type and developmental stage. When different types of cell received different types of stimulation, they regulated the expression of Id 3 through different mechanisms and signal transduction pathways. Studies by Langenfeld et at $(30,31)$ showed that inhibition of bone morphogenetic protein signaling by the selective antagonist DMH2 decreased the expression of Id1/Id3 


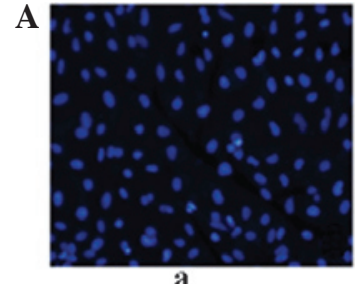

B

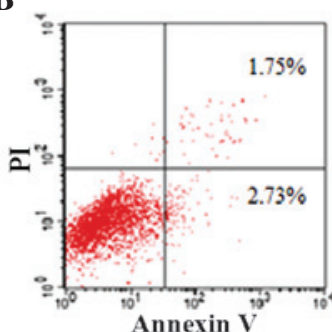

a

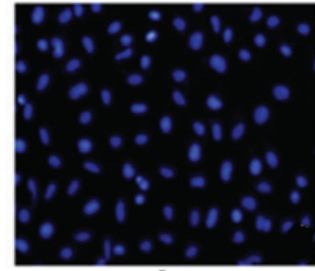

b

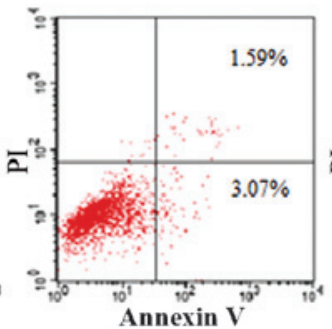

b
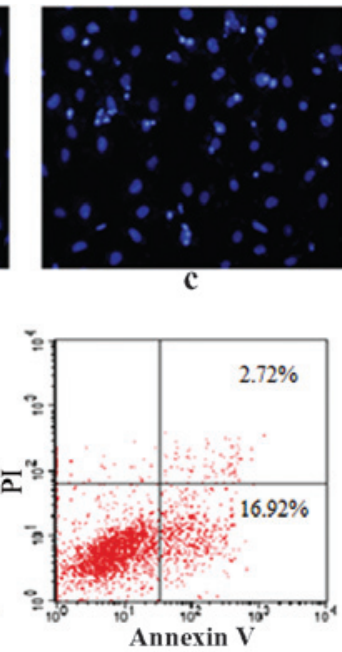

c
C

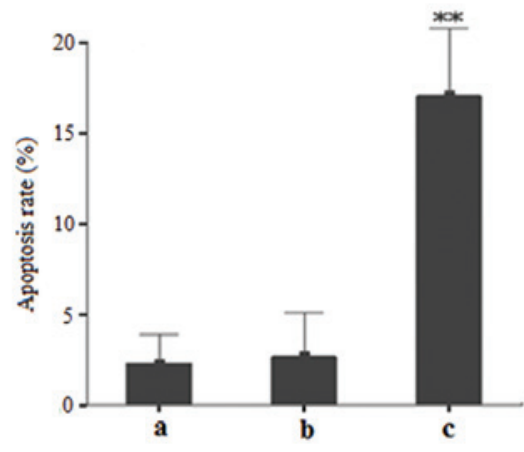

Figure 4. Id3 induces apoptosis in A549/DDP cells. (A) The morphology of apoptotic cell nuclei stained with Hoechst 33258 was observed by fluorescence microscopy (magnification, x200). (B) Flow cytometric analysis of apoptosis in pEGFP/control or Id3/pEGFP-transfected A549/DDP cells. (C) Percentages of apoptotic cells in B. Values are expressed as the mean \pm standard deviation of three independent experiments. ${ }^{* *} \mathrm{P}<0.01$ compared to pEGFP-transfected and control cells. Groups: a, untreated control; b, pEGFP transfectants; c, Id3/pEGFP transfectants (24 h of transfection). EGFP, enhanced green fluorescence protein; Id3, inhibitor of DNA binding 3; PI, propidium iodide.

and induced significant growth inhibition of lung cancer cells. Furthermore, silencing of Id3 significantly decreased the proliferation of lung cancer cells and induced cell death. However, cells stably overexpressing Id3 were resistant to growth suppression and induction of cell death induced by DMH2. By contrast, Chen et al (32) reported that suppression of Id3 expression in SCLC cells produced a significant reduction in the proliferative rate and colony formation. Another study demonstrated that co-expression of Id1 and Id3 correlated with poor clinical outcome in patients with stage III-N2 NSCLC treated with definitive chemoradiotherapy (33). The complexity of the regulatory mechanism of Id3 expression determines the diversity of its functions. These diverse effects of Id 3 in tumor cells may depend on the tumor type and stage.

The present study, for the first time, explored the effects of Id3 on the cisplatin-resistant A549/DDP human lung cancer cell line. Ectopic overexpression of Id3 in A549/DDP significantly inhibited the proliferation was induced apoptosis in vitro. Next, it will be explored whether Id3 gene expression is associated with cisplatin resistance in non-small-cell lung cancer, and whether Id3 overexpression can enhance the sensitivity of lung adenocarinoma cells to DDP. Further study is required to characterize the underlying mechanisms and the apoptotic signaling pathways triggered by Id3; furthermore, the effects of Id3 upregulation require verification in vivo. In addition, the roles or association with other Id (Id1) genes may be assessed in further studies. However, the results of the present study indicated that Id 3 may serve as a novel biomarker for NSCLC and that its overexpression may represent a novel therapeutic strategy for cisplatin-resistant NSCLC cells.

\section{Acknowledgements}

This work was supported by a grant from the National Natural Science Foundation of China (no. 81171652). The authors would like to thank International Science Editing (Shannon, Ireland) for language editing of the manuscript.

\section{References}

1. Goldstraw P, Ball D, Jett JR, Le Chevalier T, Lim E, Nicholson AG and Shepherd FA: Non-small-cell lung cancer. Lancet 378: 1727-1740, 2011.

2. Benezra R, Davis RL, Lockshon D, Turner DL and Weintraub H: The protein Id: A negative regulator of helix-loop-helix DNA binding proteins. Cell 61: 49-59, 1990.

3. Finkel T, Duc J,Fearon ER, Dang CV and Tomaselli GF: Detection and modulation in vivo of helix-loop-helix protein-protein interactions. J Biol Chem 268: 5-8, 1993.

4. Lasorella A, Uo T and Iavarone A: Id proteins at the cross-road of development and cancer. Oncogene 20: 8326-8333, 2001.

5. Ruzinova MB and Benezra R: Id proteins in development, cell cycle and cancer. Trends Cell Biol 13: 410-418: 2003.

6. Rotzer D, Krampert M, Sulyok S, Braun S, Stark HJ, Boukamp P and Werner S: Id proteins: Novel targets of activin action, which regulate epidermal homeostasis. Oncogene 25: 2070-2081, 2006.

7. Li XJ, Hata K and Mizuguchi J: Engagement of membrane immunoglobulin enhances Id3 promoter activity in WEHI-231 B lymphoma cells. Acta Pharmacol Sin 26: 486-491, 2005.

8. Lee KT, Lee YW, Lee JK, Choi SH, Rhee JC, Paik SS and Kong G: Overexpression of Id-1 is significantly associated with tumour angiogenesis in human pancreas cancers. Br J Cancer 90: 1198-1203, 2004.

9. Peng Y, Kang Q, Luo Q, Jiang W, Si W, Liu BA, Luu HH, Park JK, Li X, Luo J, et al: Inhibitor of DNA binding/differentiation helix-loop-helix proteins mediate bone morphogenetic protein-induced osteoblast differentiation of mesenchymal stem cells. J Biol Chem 279: 32941-32949, 2004.

10. Kee BL, Rivera RR and Murre C: Id3 inhibits B lymphocyte progenitor growth and survival in response to TGF-beta. Nat Immunol 2: 242-247, 2001.

11. Simbulan-Rosenthal CM, Daher A, Trabosh V, Chen WC, Gerstel D, Soeda E and Rosenthal DS: Id3 induces a caspase-3and -9-dependent apoptosis and mediates UVB sensitization of HPV16 E6/7 immortalized human keratinocytes. Oncogene 25: 3649-3660, 2006.

12. Koyama T, Suzuki H, Imakiire A, Yanase N, Hata K and Mizuguchi J: Id3-mediated enhancement of cisplatin-induced apoptosis in a sarcoma cell line MG-63. Anticancer Res 24: 1519-1524, 2004.

13. Li XJ, Zhu CD, Yu W, Wang P, Chen FF, Xia XY and Luo B: Overexpression of Id3 induces apoptosis of A549 human lung adenocarcinoma cells. Cell Prolif 45: 1-8, 2012.

14. Chen FF, Liu Y, Wang F, et al: Effects of upregulation of Id3 in human lung adenocarcinoma cells on proliferation, apoptosis, mobility and tumorigenicity. Cancer Gene Therapy 22: 431-437, 2015. 
15. Fridman E, Skarda J, Pinthus JH, Ramon J and Mor Y: Expression of multidrug resistance-related protein (MRP-1), lung resistance-related protein (LRP) and topoisomerase-II (TOPO-II) in Wilms' tumor: Immunohistochemical study using TMA methodology. Biomed Pap Med Fac Univ Palacky Olomouc Czech Repub 152: 47-51, 2008.

16. Asnaghi L, Calastretti A, Bevilacqua A, D'Agnano I, Gatti G, CantiG,DeliaD,CapaccioliS andNicolin A:Bcl-2 phosphorylation and apoptosis activated by damaged microtubules require $\mathrm{mTOR}$ and are regulated by Akt. Oncogene 23: 5781-5791, 2004.

17. Scagliotti GV, Novello S and Selvaggi G: Multidrug resistance in non-small-cell lung cancer. Ann Oncol 10 (Suppl 5): S83-S86, 1999.

18. Takara K, Sakaeda T and Okumura K: An update on overcoming MDR1-mediated multidrug resistance in cancer chemotherapy. Curr Pharm Des 12: 273-286, 2006.

19. Damdinsuren B, Nagano H, Kondo M, Yamamoto H, Hiraoka N, Yamamoto T, Marubashi S, Miyamoto A, Umeshita K, Dono K, et al: Expression of Id proteins in human hepatocellular carcinoma: Relevance to tumor dedifferentiation. Int J Oncol 26 319-321, 2005.

20. Asirvatham AJ, Carey JP and Chaudhary J: ID1-, ID2- and ID3-regulated gene expression in E2A positive or negative prostate cancer cells. Prostate 67: 1411-1420, 2007.

21. Arnold JM, Mok SC,Purdie D and Chenevix-Trench G: Decreased expression of the Id 3 gene at 1p36.1 in ovarian adenocarcinomas. Br J Cancer 84: 352-359, 2001.

22. Moon $\mathrm{C}$, Oh Y and Roth JA: Current status of gene therapy for lung cancer and head and neck cancer. Clin Cancer Res 9: 5055-5067, 2003.

23. Wilson JW, Deed RW, Inoue T, Balzi M, Becciolini A, Faraoni P, Potten CS and Norton JD: Expression of Id helix-loop-helix proteins in colorectal adenocarcinoma correlates with p53 expression and mitotic index. Cancer Res 61: 8803-8810, 2001.

24. Rockman SP, Currie SA, Ciavarella M, Vincan E, Dow C, Thomas RJ and Phillips WA: Id2 is a target of the beta-catenin/T cell factor pathway in colon carcinoma. J Biol Chem 276: 45113-45119, 2001.
25. Lee SH, Hao E, Kiselyuk A, Shapiro J, Shields DJ, Lowy A, Levine F and Itkin-Ansari P: The Id3/E47 axis mediates cell-cycle control in human pancreatic ducts and adenocarcinoma. Mol Cancer Res 9: 782-790, 2011.

26. Kamalian L, Forootan SS, Bao ZZ, Zhang Y, Gosney JR, Foster CS and Ke Y: Inhibition of tumourigenicity of small cell lung cancer cells by suppressing Id3 expression. Int J Oncol 37: 595-603, 2010

27. Pucci B, Kasten M and Giordano A: Cell cycle and apoptosis. Neoplasia 2: 291-299, 2000.

28. Hu MD, Xu JC, Fan Y, Xie QC, Li Q, Zhou CX, Mao M and Yang Y: Hypoxia-inducible factor 1 promoter-induced JAB1 overexpression enhances chemotherapeutic sensitivity of lung cancer cell line A549 in an anoxic environment. Asian Pac J Cancer Prev 13: 2115-2120, 2012.

29. Yu HG, Wei W, Xia LH, Han WL, Zhao P, Wu SJ, Li WD and Chen W: FBW7 upregulation enhances cisplatin cytotoxicity in non-small cell lung cancer cells. Asian Pac J Cancer Prev 14: 6321-6326, 2013.

30. Langenfeld E, Deen M, Zachariah E and Langenfeld J: Small molecule antagonist of the bone morphogenetic protein type I receptors suppresses growth and expression of Id1 and Id3 in lung cancer cells expressing Oct4 or nestin. Mol Cancer 12: 129, 2013.

31. Langenfeld E, Hong CC, Lanke G and Langenfeld J: Bone morphogenetic protein type I receptor antagonists decrease growth and induce cell death of lung cancer cell lines. PLoS One 8: e61256, 2013.

32. Chen D, Forootan SS, Gosney JR, Forootan FS and Ke Y: Increased expression of Id 1 and Id 3 promotes tumorigenicity by enhancing angiogenesis and suppressing apoptosis in small cell lung cancer. Genes Cancer 5: 212-225, 2014.

33. Castañon E, Bosch-Barrera J, López I, Collado V, Moreno M, López-Picazo JM, Arbea L, Lozano MD, Calvo A and Gil-Bazo I: Id1 and Id3 co-expression correlates with clinical outcome in stage III-N2 non-small cell lung cancer patients treated with definitive chemoradiotherapy. J Transl Med 11: 13, 2013. 